\title{
EUGENIO CHANG-RODRIGUEZ (1924-2019) IN MEMORIAM
}

POR

THOMAS WARD

Loyola University Maryland

Eugenio Chang-Rodríguez, destacado profesor, diplomático, lingüista e historiador de ideas latinoamericanas falleció en Nueva York el 4 de agosto de 2019 a los 94 años. La carrera de este estimado catedrático fue larga. Recibió el título de doctorado de la Universidad de Washington en 1955, enseñó en la Universidad de Pensilvania (19561961) antes de su nombramiento por el Queens College (1970-1997) y el Graduate Center(1991-1997), City University of New York. ${ }^{1}$ Ha sido asimismo profesor visitante en las universidades de Dayton, Temple, Miami, y de Southern California. Junto con su trabajo académico, se desempeñó como Ministro Consejero, Embajada del Perú, Washington, D.C. entre 1987-1988 y sirvió como delegado de la International League for Human Rights ante la Organización de las Naciones Unidas entre 1975-1984. Fue socio leal y activo del Instituto Internacional de Literatura Iberoamericana por muchas décadas, sirviendo, por ejemplo, como Presidente del Comité de Iniciativas durante la temporada que fue de 1977 a 1979. Fue uno de los miembros fundadores de la Academia Norteamericana de la Lengua Española, institución de la cual seguía formando la junta directiva y sirviéndose como director del Boletín de la Academia Norteamericana de la Lengua Española. Fue también académico de número de la Academia Peruana de la Lengua y correspondiente de la cubana y española. Fue miembro correspondiente de la Hispanic Society of America. Entre las varias distinciones había recibido la Medalla de Honor del Congreso del Perú (1987), Orden al Mérito del Gobierno Peruano (1987), el doctorado honoris causa de la Universidad Ricardo Palma (2014), el de la Universidad Antenor Orrego (2013), el de la Universidad nacional Mayor de San Marcos, (2012), el de la Universidad Nacional de Atenas (Grecia, 2008), el de la Nacional Enrique Guzmán y Valle (2004), y el de la Universidad Nacional Federico Villarreal (1979). Fue profesor honorario de la Universidad Privada Antenor Orrego,

\footnotetext{
Sigo en parte "Curriculum Vitae de Eugenio Chang-Rodríguez", por Richard Cacchione Amendola", en Homenaje a Eugenio Chang-Rodriguez, eds. Thomas Ward y Richard Cacchione, Lima: Universidad Ricardo Palma, Lima, Perú, 2017, pp. 251-288.
} 
de la Universidad Nacional Mayor de San Marcos, y de la Universidad Inca Garcilaso de la Vega. Durante el largo transcurso de su vida profesional publicó una veintena de libros y un centenar de artículos.

Las trayectorias de las investigaciones del profesor Chang-Rodríguez eran diversas. Desde su primer libro, La literatura política de González Prada, Mariátegui y Haya de la Torre (1957) a su penúltima, Pensamiento y acción en González Prada, Mariátegui y Haya de la Torre (2012), ha mostrado interés en el pensamiento político y social peruano. De esta trayectoria es Poética e ideología en José Carlos Mariátegui aparecido en 1983 y Una vida agónica. Víctor Raúl Haya de la Torre (2007). En la Revista Iberoamericana, órgano del Instituto Internacional de Literatura Iberoamericana, publicó artículos sobre "El ensayo de Manuel GonzálezPrada" (1976), "El indigenismo peruano y Mariátegui” (1984) y "Proyección de lo indígena en las literaturas de América Hispánica" (1984). Estas investigaciones le abrieron las puertas al partido político APRA, la Alianza Popular Revolucionaria de América, interés que resultó en Opciones politicas peruanas (1985, $2^{\mathrm{a}}$ ed. en 1887), y APRA and the Democratic Challenge in Peru (1988), editado con Ronald Hellman. Asimismo, de sus estudios lingüísticos, brindó The Romance Languages and their Structure: Frequency Dictionary of Spanish Words (1964) y colaboró con Colin Smith y Manuel Bermejo en el Collins Spanish Dictionary. Spanish English. English Spanish. Ha dejado memorias llenas de datos sobre nuestra profesión, Entre dos fuegos. Reminiscencias de las Américas y Asia (2005) y Entre dos fuegos. Reminiscencias de Europa y África (2009).

Fue autor de textos universitarios como Latinoamérica: su civilización y su cultura (cuatro ediciones), traducido al chino (1990) y coreano (2000). La tesis que corre por los renglones de este libro es el ideal de la unidad de los diversos sectores étnicos y raciales de Latinoamérica. Desde la perspectiva lingüística, publicó el libro de texto Continuing Spanish: A Project of the Modern Language Association, de dos ediciones $(1967,1974)$. En sus últimos años volvió a sus raíces en Trujillo, Perú, para interesarse en las migraciones chinas a las Américas, a las cuales la historia de su propia familia se integró. De estas inquietudes resultaron Diásporas chinas a las Américas (2015). El profesor Chang-Rodríguez se mantuvo ocupado hasta sus últimos días contribuyendo al volumen 6 de Historia de las literaturas en el Perú (2019) con un capítulo, "Tradición e innovación. El ensayo peruano en las primeras décadas del siglo XX".

En la historia de las ideas, en la política y diplomacia peruana y latinoamericana, en la lingüística (también fue muy activo en International Linguistic Association) y en las mochilas de miles de estudiantes estadounidenses, chinos, y coreanos, que contenían una de las ediciones de Latinoamérica: su civilización y su cultura, las resonancias de Eugenio Chang-Rodríguez son poderosas y variadas. Tanto los círculos intelectuales de Lima como los de los peruanistas de Nueva York echan de menos a su conversación placentera y jovial. 